\begin{tabular}{c} 
journal homepage: http://ijiemjournal.uns.ac.rs/ \\
International Journal of Industrial \\
Engineering and Management \\
volume $11 /$ No $3 /$ September $2020 / 192-204$ \\
\hline
\end{tabular}

Original research article

\title{
Implementing a maintenance strategic plan using TPM methodology
}

\author{
G. Pinto ${ }^{a}$, F. J. G. Silva ${ }^{a}{ }^{*}$, N. O. Fernandes ${ }^{b}$, R. Casais ${ }^{a}$, A. Baptista ${ }^{a}$, C. Carvalho $^{a}$ \\ a ISEP - School of Engineering, Polytechnic of Porto, Mechanical Engineering Department, Porto, Portugal \\ ${ }^{b}$ Instituto Politécnico de Castelo Branco, Mechanical Engineering Department, Castetelo Branco, Portugal
}

\begin{abstract}
A B STR ACT
The market globalization and worldwide competition has raised the level of demand in the industrial sector. Due to this aggressive competitiveness, some management strategies and tools needed to start to be applied in the industry. For example, maintenance has become increasingly important in the production planning and strategy of some companies. This work focuses on the implementation of a strategic maintenance plan, applied in an industrial context, namely in a company of Clutches and Hydraulic Controls. The Total Productive Maintenance (TPM) methodology application was worked on and implemented at two sections, CNC Lathes and CNC Machining Centers, to focus on eliminating losses due to inefficiencies. In this way, the main problems detected in relation to the cells were eliminated. New autonomous maintenance procedures (AM) and preventive maintenance plans with well-defined schedule were also developed. The results obtained were very positive: there was a decrease of $23 \%$ in breakdowns in CNC lathes sector and $38 \%$ in CNC machining centers sector. In global terms, there was an increase in the availability of the machines and the Overall Equipment Effectiveness (OEE) of approximately 5\%. The implementation procedure and the compromise adopted by the whole company staff and management was the secret to success.
\end{abstract}

\section{ARTICLE INFO}

Article history:

Received June 23, 2020

Revised September 15, 2020

Accepted September 16, 2020

Published online September 29, 2020

Keywords:

Autonomous maintenance;

Maintenance; Machining;

5S; OEE; MTBF; MTTR;

Continuous Improvement;

Process Optimization; TPM;

Failure Analysis

*Corresponding author:

Francisco J. G. Silva

fgs@isep.ipp.pt

\section{Introduction}

The worldwide globalization of the markets brought many advantages, but also dramatically increased the industry competitiveness. The competition to which companies are now subjected forces them to invest in new strategies. For example, in order to achieve success, some companies focus on customers' needs, as well as their loyalty. Globalization, undoubtedly, has brought competitiveness to the entire industry, and metallurgy is no exception. To ensure business competitiveness and its financial health, constant improvement actions are necessary with the objective of increasing profitability and reducing waste associated with the process [1-3]. Therefore, there is a clear company objective: to reduce or eliminate the causes associated with equipment failures, machine downtime and non-conformities associated with production times.

One of the approaches to make the companies more competitive is Total Productive Maintenance (TPM). As a complement to this tool, extreme importance is also given to the implementation of changes in the process, strong communication and compromise among all workers. There is a great concern on the part of the leadership to involve all 
workers in the transformation and implementation of the procedures. Total Productive Maintenance (TPM) aims to eliminate losses, reduce costs and downtime. One way to get success with this methodology is to use well-defined maintenance plans. For this reason, this methodology is widely used in the industry in the last decades with excellent results. For instance, Reis et al. [4], showed an increase of $18.5 \%$ of Operating Income in a company producing brakes drums for the automotive industry using TPM tool. On the other hand, Ribeiro et al. [5], in a study which the main objective was to improve the availability of a critical production line through TPM and supported by Lean, achieved increased performance indicators, such as: MTBF, MTTR and availability by $25 \%, 13.3 \%$ and $1.2 \%$, respectively. Thorat et al. [6], studied the TPM implementation in a manufacturing company of injection moulding parts for the automotive industry, and Sharma et al [7] also used the same tool to improve the manufacturing performance, reinforcing the importance of effective training and skill development of the workers. Otherwise, Suryaprakash et al. [8], presented a study in a mechanical workshop able to manufacture steering boxes, which main goal was to improve the Overall Equipment Effectiveness (OEE). The results obtained were good, having increased the OEE by $6.06 \%$. This study sought to improve the availability of the machines, reducing equipment downtime. High importance is also attributed to the creation of a commitment culture about the equipment handling, with the aim of increasing the useful life of machines and improving the quality of manufactured products. In this work, a preventive maintenance plan (PMP) is presented to be implemented in a Hydraulic Clutches and Controls manufacturing company, based on the TPM methodology. The management encompasses the maintenance of the equipment, which must be seen as a global objective of the company, among all workers, to be carried out not only by the maintenance technicians but also from the management to the workers who use the equipment daily. The implementation of the TPM will be carried out with the unconditional workers support, always being heard by the management to make them feel useful and integrated into this new company phase.

This article is structured as follows: after the introduction, section 2 performs a review about the most relevant literature related to the subject of this work. Section 3 describes the methods associated with TPM and how they were used in this work. In section 4 , the results are presented, followed by the conclusions and the proposals for future work in section 5 .

\section{Literature review}

The globalization of markets has not only brought thoughtful changes in policies, economy and culture, but it has also brought free trade, with free flow of capital between nations, bringing as well increased competitiveness, with market demanding higher quality products at competitive prices [9]. To meet this market demand, it is necessary that companies reorganize themselves and become much more competitive. For this, companies must eliminate all waste associated with production processes [10]. The common type of waste found at manufacturing companies are breakdowns due to machine failures $[9,11]$ and the best way to minimize them is the adoption of policies for a strategic maintenance management [12,13]. According to BS EN 13306: 2010 standard [14], maintenance is defined as the set of operations necessary to re-establish equipment to be available and accomplish the planned tasks. Monchy [15] establishes two important milestones in the product's life cycle, entry into service and death. He also highlights three distinct phases, between these two milestones. These phases are Child, Adolescent/Adult and the last, Geriatric phase. In this Child phase, there is a decrease in the first typical diseases. In the Adolescent/Adult phase, diseases are randomly revealed and in the Geriatric phase, there is a tendency for the number of diseases to increase. Nowadays, with the technology evolution, namely in computing, maintenance has also evolved benefiting from that evolution. Now, it is possible to gather a large amount of information in a short time, work on it and make decisions based on information about general performance of the equipment [1].

The new demand from the market also brings a greater demand in relation to quality requirements. As a result, equipment becomes more complex and maintenance is therefore affected. In response to new requirements, tools emerged in the maintenance strategy, such as Reliability-Centered Maintenance (RCM), Total Productive Maintenance (TPM), TQMain - Total Quality Maintenance, RBI - Risk-Based Inspection [16]. Among these tools, TPM and RCM are widely used in the industry. TPM involves all workers and aims to maximize the efficiency, eliminating waste. The RCM is based on the failure mode of the equipment and its consequences [1,12].

In order to induce a homogeneous flow of work into a company, coordination between all departments is essential. The maintenance department is no exception and its goals must be in line with the objectives and plans defined by the company, according 
to Coetzee [17]. Maintenance is part of the ancillary activities that directly affect product costs, quality and reliability [9].

An indispensable procedure for the TPM success is the involvement of the whole structure of the company, from the head to the remaining staff, who need to be always committed to the objectives outlined and with the responsibilities assigned to each one. The TPM maximizes the productivity and availability of equipment, creating a motivating environment to encourage the participation of workers to be better than the competitors in quality, reliability, cost savings and creativity [18]. The activities began to be well planned and structured, the workers are responsible for taking care of the equipment in which their interact daily. The concept of "autonomous maintenance" emerged as one of the main characteristics of the TPM [19]. This methodology uses preventive maintenance and autonomous maintenance. Therefore, cleaning, inspection, component replacement and planned repairs are included in the autonomous maintenance, to avoid production downtime and control the machine's service life [20].

In fact, TPM is based on a continuous improvement process. Individuals, teams, all company employees are constantly evolving, either to learn or to share the knowledge and skills already acquired. In fact, all this effort to reduce waste is aimed at increasing OEE, which is directly linked to the performance, quality and availability of equipment [1,9,21]. In the companies' organizational structure, it is normal to find several departments with different functions and goals, for example, the production concerns with manufacturing products in schedule and with the desired quality, and logistics with the delivery performance. In the case of Maintenance, it should focus on ensuring the greatest possible equipment availability. To assist maintenance, there are some Lean tools, such as 5S and SMED methodology $[22,23]$. The $5 \mathrm{~S}$ refers to five Japanese words, Seiri (Organize), Seiton (Fix), Seiso (Clean), Seiketsu (Normalize), Shitsuke (Discipline) [24]. According to the study of Pinto et al. [1], referring to a rubber products company for the automotive industry, there was a need to follow the IATF 16949: 2016 standard [25]. For the company to comply with the standard requirements, it was necessary to update the indicator records such as MTBF, MTTR and OEE. In this transition, waste was detected in the press setup processes, which forced the application of the SEMED methodology. The $5 \mathrm{~S}$ tool was also used to make maintenance services more efficient. These changes introduced with the help of these tools brought a reduction in setup time by $11 \%$ and an increase in OEE to $90.22 \%$. Compared with the world reference values, $85 \%$, this value is very good. Moreira et al. [9], studied on the graphic printing area and explored and mitigated the causes that affected product quality and the low availability index of the machines. At the end, they achieved an increase of $2 \%$ in OEE and a reduction in production costs with non-conformities by $32.9 \%$. In a study about the storage of material for maintenance, Pombal et al. [26], applied the $5 \mathrm{~S}$ and visual management, having obtained a reduction in the operation time of approximately 70\%. The main contribution for the obtained results was achieved remodelling and managing the stock of materials through the Kanban system, having achieved a 30\% reduction in repair time.

In this study, it is proposed a maintenance model, to be applied in the company, having as main goals: (1) reduce the number of curative interventions on two identified CNC machining cells; (2) reduce the time spent in maintenance interventions, and (3) reduce breakdown time due to unforeseen machine failures.

\section{Methods}

The methodology used, to improve machine availability and downtime, was the implementation of TPM. In this chapter, it will be present the structure of the TPM used.

\subsection{TPM - Defining pillars to be used}

As can be seen in the literature on TPM, there are several ways to implement it. In this work, the pillars considered are (a) Main problems elimination; (b) Autonomous maintenance; (c) Planned maintenance; and (d) Formation and training. Regarding the elimination of the main problems, we opted for analysis and identification of the main problems and mitigation of their causes so that they can be reduced or eliminated. In autonomous maintenance (AM), workers need to assume a higher grade of responsibility for maintenance routines. In the planned maintenance, the workers or maintenance technicians carry out the activities with the objective of keeping the equipment operational and, thus, avoiding unexpected stoppages. In education and training, workers receive skills in the theoretical and practical component about the machines to avoid unexpected downtime. It was decided to elaborate internal documents with the procedures regarding the maintenance tasks with the periodicity of their execution. The plans, of 
autonomous and planned maintenance were structured by type of machine and date of frequency.

\subsection{Diagnosis - conditions before TPM application}

To initiate TPM, it is necessary to make a diagnosis. A multidisciplinary team was created for this task. To fine-tune the most appropriate strategy to be followed by the company, the relevant points were organized. Maintenance planning stands out with some deficiencies, such as:

- weekly cleaning is also not effective for all equipment;

- there is no knowledge about the $5 \mathrm{~S}$ methodology;

- there are no records about maintenance interventions or a history of malfunctions;

- there is no database with a history of maintenance costs;

- there was no software to support maintenance;

- there is no evidence of analysis and study on the causes of malfunctions, and

- there is no history of stock management regarding spare parts and corresponding replacement.

After this diagnosis, a strategy for the beginning of the TPM implementation was formulated and it was decided not to implement the eight pillars of the standard TPM. It was decided to define practical and simple documents that would allow a quick and efficient implementation.

\subsubsection{Collection of machine failure data for three months}

To prepare the diagnosis, it was necessary to carry out a survey on the downtimes occurred in $\mathrm{CNC}$ lathes and $\mathrm{CNC}$ machining centres and the corre- sponding causes of each breakdown, in a period of three months. Table 1 shows the values organized by categories: (1) human error, (2) lack of preventive maintenance (PM) and (3) end of part life.

As previously discussed, the company's biggest identified problems are organization and cleanliness. These problems are directly linked to the way workers develop their activities on the machine and the way the equipment is handled. Since the beginning of the TPM implementation process, namely the AM, there was an indispensable need to implement the $5 \mathrm{~S}$ as a starting point, creating the necessary discipline in the collaborators and a disruption with the initial situation. Thus, a series of documents were created, such as the $5 \mathrm{~S}$ implementation schedule, list of measures to be implemented, audit planning, $5 \mathrm{~S}$ audit sheet, layout of the document to identify the situation before and after the $5 \mathrm{~S}$ implementation. For the successful $5 \mathrm{~S}$ implementation, internal audits were also weekly scheduled with the focus on identifying problems associated to the compliance with the implemented measures.

\subsection{TPM implementation}

The steps used to implement the TPM are described in Table 2.

\subsubsection{1st Pillar - Main problems elimination}

The 1st pillar is characterized as the continuous analysis of problems and the definition of corrective and preventive actions, with a focus on continuous improvement. This pillar inspires a proactive attitude in defining actions to reduce or eliminate downtime associated with a detected problem. The organized way of respecting the principles of this pillar is, initially the losses are determined and the main problems are identified, then a cause analysis is done, then the corrective actions are defined and implemented and finally, standards are normalized.

\subsubsection{Step 1 - Determine losses and main problems}

Table 1. Time wasted in breakdowns at CNC Milling Centers and CNC Lathes (hours)

\begin{tabular}{lcc}
\hline Breakdown causes & CNC Lathes & CNC Machining Centers \\
\hline Human error & 116 & 291 \\
Lack of preventive maintenance & 21 & 55 \\
End of part life & 68 & 127 \\
\hline Total & 207 & 473 \\
\hline
\end{tabular}


At the beginning of this process, no records of machines' failures are available, because this was the practice in the company. Thus, it was necessary to identify the reasons behind this practice. Therefore, it was found that the reason for not having such records was associated with the following factors: (a) the difficulty for operators to identify the malfunction, (b) the workers' lack of knowledge about the equipment, (c) the lack of communication between workers. After verifying this scenario, corrective measures were proposed: purchase and implement maintenance control software and planning technical training sessions for the workers.

After the implementation of the software and training, data related to machine failures and prob- lems were collected and recorded. After collecting and registering a significant number of data, it was possible to identify the problems associated with the equipment. This analysis identified a problem related to the refilling of the collant fluid tank and another one related to the sliding of the safety door of the machines. The identification of these two problems triggered some corrective measures.

\subsubsection{Step 2 - Causes analysis}

A cause analysis was carried out using the "5 whys?" asking maintenance technicians, managers, and production workers to participate in these sessions. Thus, actions were defined for the identified

Table 2. Work method implemented

\begin{tabular}{|c|c|}
\hline Tasks & Description \\
\hline $\begin{array}{l}\text { Survey and analysis of maintenance manuals of } \\
\text { existing machines in the company. }\end{array}$ & $\begin{array}{l}\text { Initial document to register the maintenance activities to be carried out accord- } \\
\text { ing to the planning. Current } \\
\text { information about tasks to be performed and } \\
\text { their frequency. }\end{array}$ \\
\hline $\begin{array}{l}\text { Crossing of information from the manuals, their } \\
\text { use and the } \\
\text { know-how of maintenance workers. }\end{array}$ & $\begin{array}{l}\text { Creation of the document with planned and autonomous maintenance activi- } \\
\text { ties and respective checklist to help. }\end{array}$ \\
\hline $\begin{array}{l}\text { Machine failure data collection. Data period: } 3 \\
\text { months. }\end{array}$ & $\begin{array}{l}\text { Data collected for analysis and decision help: Type of } \\
\text { failure, downtime, reason for machine breakdown and maintenance. }\end{array}$ \\
\hline $\begin{array}{l}\text { Four pillars of the TPM } \\
\text { implementation. }\end{array}$ & As described in section 3.1 \\
\hline Machine failure data collection. & $\begin{array}{l}\text { Analysis and comparison of the data collected before and after the impleme - } \\
\text { tation of the TPM, made during the diagnosis. }\end{array}$ \\
\hline $\begin{array}{l}\text { Check after th ee months of the TPM } \\
\text { implementation. }\end{array}$ & $\begin{array}{l}\text { Improvements check after p eventive and corrective actions applied according } \\
\text { to the TPM implementation. }\end{array}$ \\
\hline
\end{tabular}

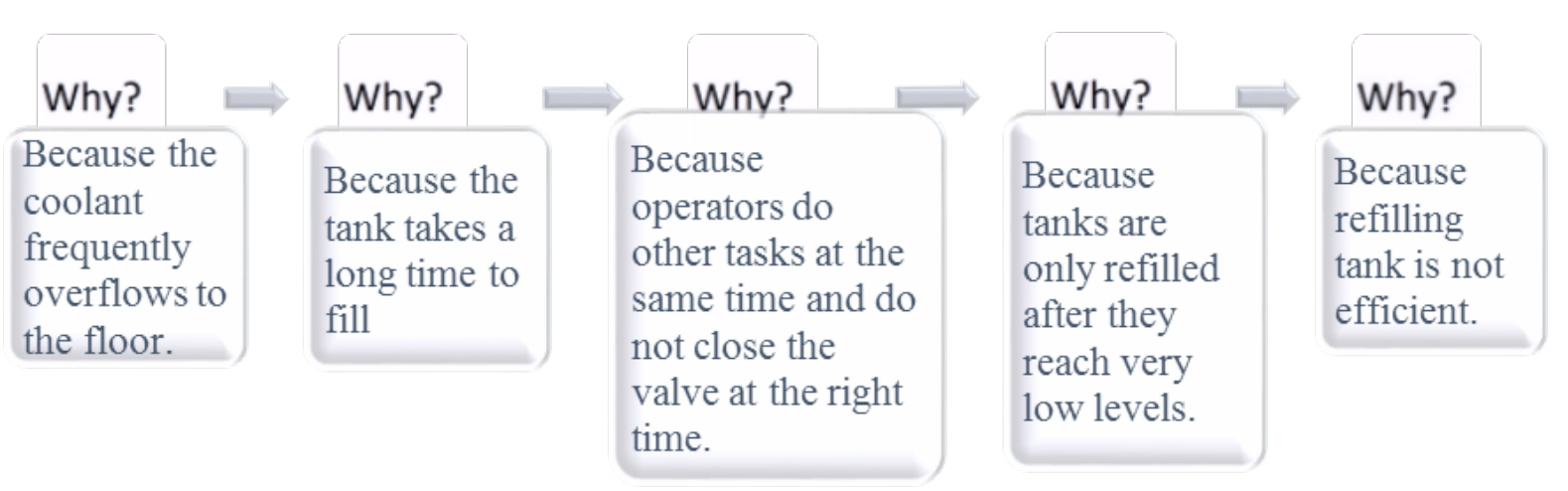

Figure 1. "5 Why" - Problems with coolant tank fillin 
problems in order to eliminate them.

A problem with the refilling of the coolant fluid tank was identified due to it leaving the circuit through the chip extractor, together with the chips. This problem causes the need for refilling the tank frequently. The refilling of the tank is not done correctly by the workers due to lack if care of them in this operation, occurring severe leakages on the floor. Figure 1 shows the application of the " 5 whys" tool to solve the problem related to filling the tank.

Initially, the strategy was to sensitize operators to be more careful, but this solution would only have short-term benefits. Thus, it was necessary to think about another solution. In the next chapter, it will be explained.

The cause analysis regarding the sliding of the security door using the " 5 why?" is shown in figure 2. The machines have a security system in order to avoid it to work if the door is open or not properly closed.

The lack of cleaning causes some inconvenience at the productive level. No routine was identified regarding the cleaning of the door sliding rails, being done only when essential for the operation of the machine, as a last resort, figure 3 a.

\subsubsection{Step 3 - Define and implement corrective actions}

For the resolution referring to the tank of coolant fluid, it was decided to install a self-refilling and collant filtration system. Thus, this new system replaced the manual system. With the new automatic system, the opening and closing of the valve is now controlled with the help of a float, figure $3 \mathrm{a}$. This new system, figure $3 \mathrm{~b}$, also allowed the reuse of the coolant once it is filtered and reintroduced into the cooling system. With this update, it is expected that the frequency of the coolant oil replacement will change from monthly to annual, which will induce a decrease in cost.

In the procedure created regarding the cleaning process, the strategy of recording activities is highlighted to ensure that they were carried out. For example, in the peripheral area of this machine, cleaning must be taken into account when changing shifts. Workers are penalized if the next shift starts with machine and surrounding area dirty. In the new procedure are the instructions for carrying out the described operations and, after the execution of the procedure, the workers must sign the sheet as a form of confirmation.

\subsubsection{Step 4 - Create and normalize}

Standardization is essential to systematize tasks and thus facilitate the learning of new healthy habits. It also helps in identifying deviations in the process

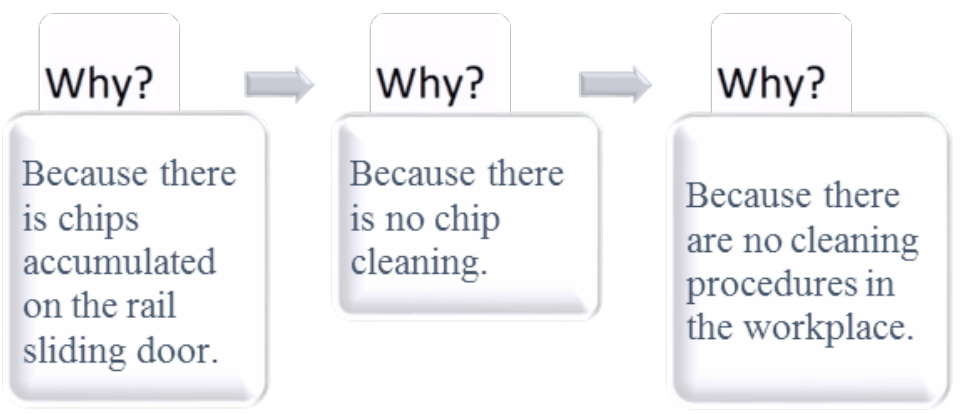

Figure 2. "5 Why" - Safety door sliding problems

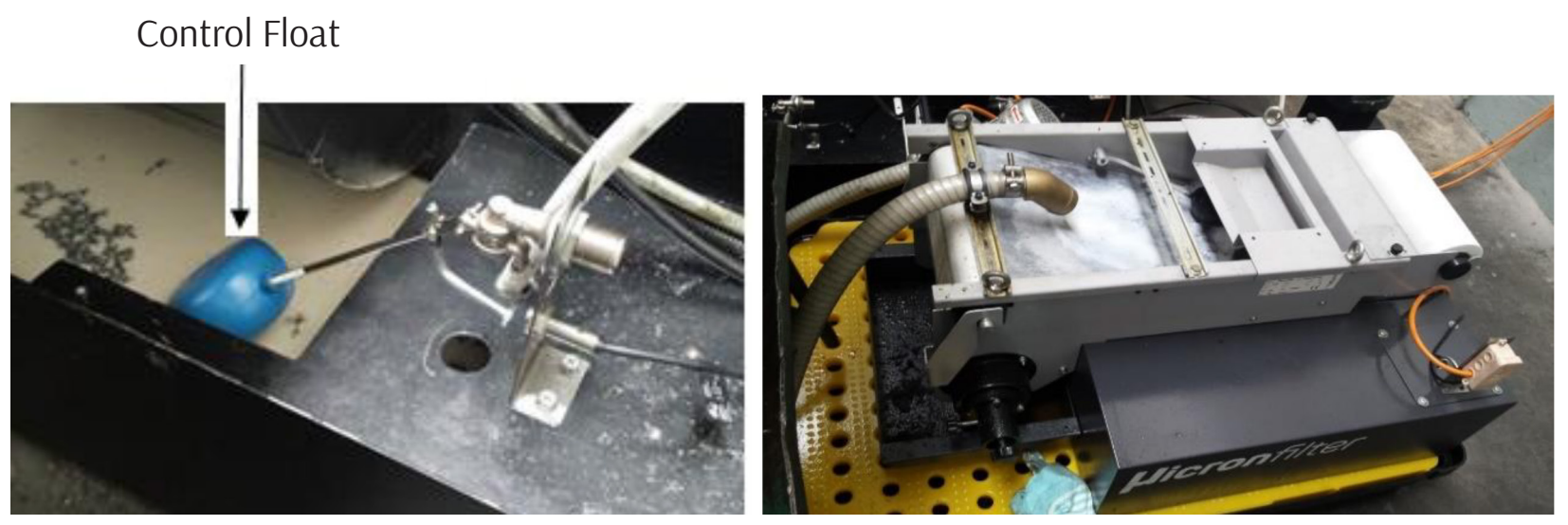

Figure 3. Coolant self-supply and filt ation system, (a) Control Float and (b) automatic system 
and obtaining useful indicators. Regarding the example of the problems with the coolant tank, a procedure was created to be applied to all tanks. Thus, employees work with the same working conditions regardless of the tank they have nearby. The most relevant steps to be applied were: (a) Install a float to control the refrigerant level in the tank; (b) adding a filter to the system to extend the life of the machine and oil; (c) adding an activity under the responsibility of AM to weekly control the oil quality; (d) include, in the planned maintenance procedure, an annual activity to replace all coolant.

Regarding the problem identified in the sliding security door, cleaning procedures were created for the machines and the peripheral area, as well as in other workstations, making these tasks mandatory, including the control of their registration.

\subsubsection{2nd Pillar - Autonomous Maintenance}

As already mentioned in the previous chapter, $\mathrm{AM}$ is performed by the workers assigned to the CNC machines. The premises followed in the implementation of maintenance in order to achieve maximum efficiency are: (a) Perform basic inspection of previously identified machinery and equipment; (b) Standardization of maintenance activities, including cleaning and inspection; (c) Carry out maintenance activities independently; (d) Continuously improve equipment and process quality. The basic inspection of machines and equipment aims to improve or create access for maintenance, avoid dirt and leaks and overcome anomalies. The machines studied in this work are MAZAK machines, which have been developed and designed to facilitate access to lubrication and cleaning, and there is no justification for any type of equipment changes. In this sense, the first stage of this process was not considered. The standardization of maintenance activities, guarantee and assist the performance of AM. This step consists of implementing cleaning procedures according to the essential needs to guarantee a safe and clean environment. The definition of maintenance activities should include, in the AM procedures, (i) maintenance manuals of the analysed machines, as well as their frequency and recommendations; (ii) discussion of the problems and anomalies that workers face daily, as well as the frequency of maintenance activities to ensure the prevention or elimination of the identified problems. Strategically, it was possible to normalize maintenance activities per type of cell, elaborating a maintenance plan for Lathes and another one for CNC Machining Centers. For daily AM, a shift label was created. Each operator must ensure that, when changing shifts, the cleaning of the parameters described in the checklist is cleared. The AM plans are divided into three distinct periods, daily, weekly and monthly, depending on the identified needs. To carry out maintenance activities independently, a meeting was held with workers to explain what is intended and how to do it. Theoretical-practical training on $\mathrm{AM}$ was planned, where the concepts and ideas of operation were explained. It was pointed out to operators that the involvement, cooperation and communication between maintenance and production would be essential to protect the machines, to guarantee long durability and good quality of the manufactured products. In addition to shift change forms, which reflect the commitment to carrying out daily AM activities, weekly and monthly checklists were also implemented. Continuous improvement is the main objective after the creation of AM procedures. The standard activities and the documentation of these activities have the objective of disciplining the workers for their accomplishment, but also showing the preponderant importance of the workers in making suggestions for improvements, and implementation of good practices. In order to guide workers on these good practices, a document was prepared and made available to them in the workplace, allowing suggestions to be made.

\subsubsection{3rd Pillar - Planned maintenance}

In the survey of the activities included in the planned maintenance, namely in the production cells covered by this work, it was found that there are several points to be improved, for example: (a) the activities periodicity does not correspond to the recommended by the machine brand and does not cover the machine needs, (b) the clear definition of the maintenance time, as well as the person who is responsible for its execution, (c) the planned maintenance times do not apply due to incompatibility with production planning, (d) absence of a maintenance information control system to assist and check the different implementation steps.

According to the TPM 1st pillar, all maintenance actions that require skills and technical knowledge will be included in the PM plans.

\subsubsection{Implementation of preventive maintenance plans}

As in $\mathrm{AM}$ case, the machines manuals and the maintenance technicians experience were crucial to carry out a plan that could take advantage of the com- 
pany's experience and of the recommendations of the machines'manufacturers.

\subsubsection{Requests for curative maintenance intervention}

Requests for curative intervention are a consequence of equipment malfunctions or anomalies. Any worker in the company has a responsibility to report system failures. In the procedure, it is stipulated that the first intervention belongs to the worker who detected the damage. The maintenance worker receives the notification of the anomaly. After that, a curative maintenance service order is created and after this has been resolved, the maintenance team has a duty to fill in some information in the system, such as the number of hours spent, spare parts used, description of the problem and the respective description of the intervention.

\section{Results}

In this section, the results of this work are presented, giving relevance to: the reduction in downtime achieved through the maintenance carried out by the Production workers, the implemented actions effectiveness, the indicators evolution and all the non-measurable results achieved through this work.

\subsection{Eliminating the main problems}

The problem detected regarding the filling of the coolant in the tank cannot be considered a malfunction, however, it is a problem that causes time loss and excessive expenses. After installing the supply and filtering system, its maintenance and respective coolant replacement changed from 3 months to annual. Therefore, refrigerant exchange activity has a four-fold impact on planned downtime. Coolant replacement time is 3 hours a year instead of the 12 hours previously spent. Still associated with this update, operators no longer have the task of filling the tank. Due to the fact that this task is manual, it also brought a lot of waste, both in terms of oil and the time needed to carry out the task. The monetary impact of this improvement is also significant.

In the sliding door problem, it is difficult to estimate the downtime caused by the sliding door, but it is a fact that this problem causes short stops in production. These stops correspond to the time that workers spend cleaning the assigned area into the machine. This task was included in the form when changing shifts.

Although it was not possible to quantify the cost caused by this problem, there is no doubt that this improvement had a great impact both on the evidence of the clean state of the machines and on the elimination of the small stops that existed prior to this action.

\subsection{Maintenance performed}

In the shift change, an AM procedure was implemented showing a good receptivity of the workers. This procedure allows for the recording of the equipment conditions at the beginning and end of each shift. After three weeks, this implementation was audited and there was a need to take a new approach to workers. The performance of the monthly AM had a positive evolution, once the maintenance plan was fulfilled.

\subsection{Evolution of indicators}

After the application of corrective, preventive and improvement actions, AM's activities, and respective investment in training actions, it was verified an effective reduction in equipment downtime, which translates into an increase in machine availability. In the case of the CNC Machining Centres, downtime has decreased although there were two unforeseen stops, one due to human error and the other caused by the end of life of a bearing. As can be seen in Table 3 and Figure 4, downtime has always been greater than 100 hours per month and is currently less. The reduction in stops was $23.4 \%$ and the number of interventions decreased by $38.1 \%$.

Table 3. Time [hours] and the reason for stopping at CNC Machining Centers

\begin{tabular}{|c|c|c|c|c|c|c|c|c|}
\hline \multirow[b]{2}{*}{ Reason } & \multicolumn{6}{|c|}{ Months } & \multicolumn{2}{|c|}{ Number of Stops } \\
\hline & 1st & 2nd & $3 r d$ & 4th & 5 th & 6 th & 1st to 3rd & 4th to 6th \\
\hline End of part life & 72 & 55 & 0 & 192 & 0 & 48 & 5 & 4 \\
\hline Human error & 72 & 62 & 157 & 36 & 38 & 24 & 10 & 4 \\
\hline Lack of PM & 18 & 23 & 14 & 8 & 13,5 & 3 & 6 & 5 \\
\hline Total. & 162 & 140 & 171 & 236 & 51,5 & 75 & 21 & 13 \\
\hline
\end{tabular}


In table 4 and figure 5 is possible to see that there was a reduction in machine downtime by $37.3 \%$, and the number of interventions reduced by $16.7 \%$ regarding CNC Lathes.

After carrying out an audit of the ISO 9001 management system and analysing its results regarding OEE, MTTR and MTBF, the data show a very positive evolution. The data can be seen in Table 5 . For the studied cells, the stopping hours for curative maintenance and the number of failures were analysed. In short, the "theoretical time available - time spent on interventions"/"number of interventions" was used. Table 5 also shows the MTBF values obtained. For the two cells under study, the stopping hours for curative maintenance and the "number of occurrences"/failures" were analysed. In short, the time spent on "interventions"/"number" of interventions were used. Table 5 also shows the Availability and OEE values.

\subsection{S Results}

The implementation of $5 \mathrm{~S}$ brought very important gains in the organization and in the production

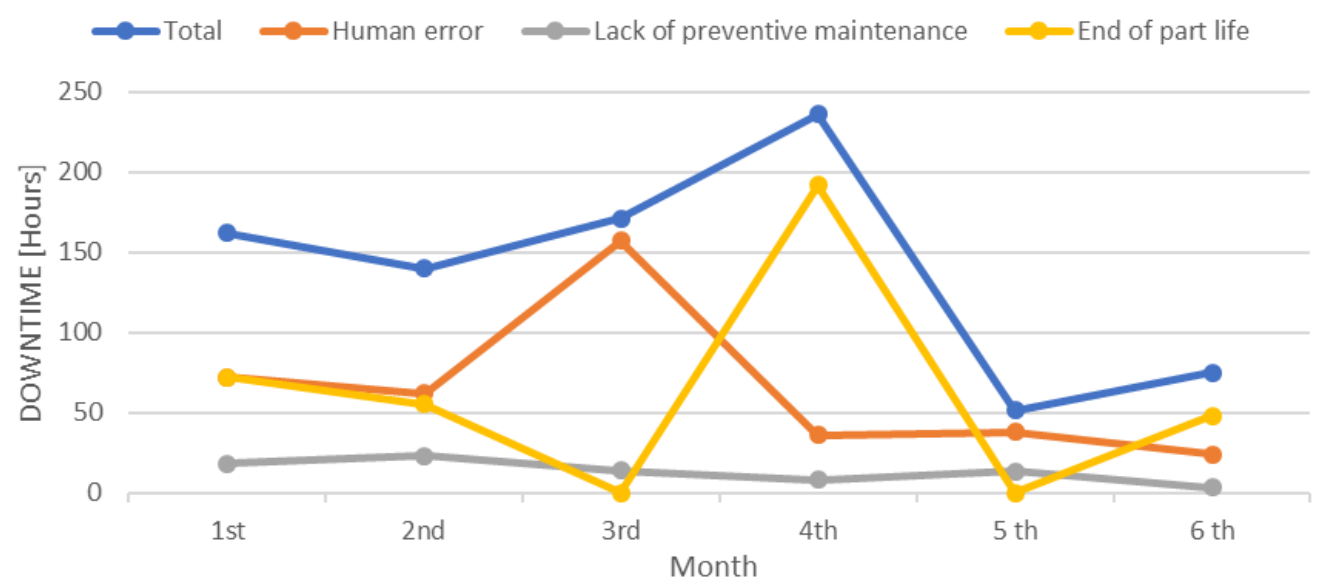

Figure 4. CNC Milling center's downtime

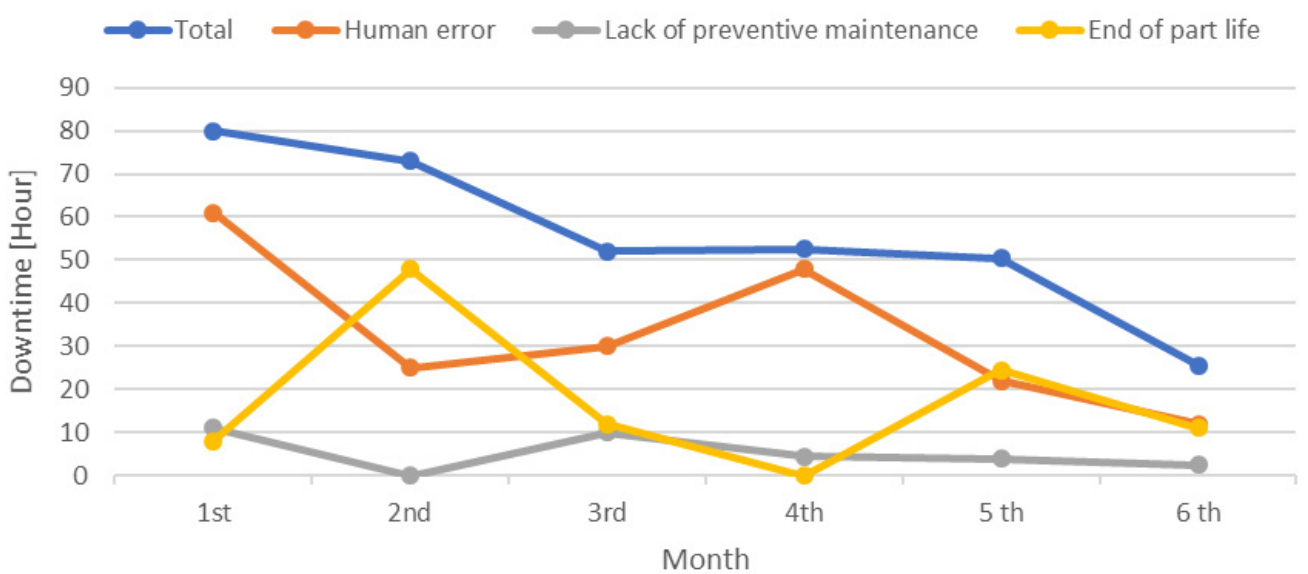

Figure 5. CNC Lathe's stopping time

Table 4. Time [hours] and reason for stopping at CNC Lathes

\begin{tabular}{|c|c|c|c|c|c|c|c|c|}
\hline \multirow[b]{2}{*}{ Reason } & \multicolumn{6}{|c|}{ Months } & \multicolumn{2}{|c|}{ Number of Stops } \\
\hline & $1 s t$ & 2nd & $3 r d$ & 4th & 5 th & 6 th & 1st to 3rd & 4th to 6th \\
\hline End of part life & 8 & 48 & 12 & 0 & 24,5 & 11 & 4 & 3 \\
\hline Human error & 61 & 25 & 30 & 48 & 22 & 12 & 9 & 8 \\
\hline Lack of PM & 11 & 0 & 10 & 4,5 & 4 & 2,5 & 5 & 4 \\
\hline Total. & 80 & 73 & 52 & 52,5 & 50,5 & 25,5 & 18 & 15 \\
\hline
\end{tabular}


process. After the first phase of awareness and training of the $5 \mathrm{~S}$ teams, the workers started to apply their knowledge on the factory floor. In this transition, workers were essential because they shared their experiences and opinions about their workplace. Figures 6 shows the result of the changes. To ensure that the new habits are maintained, an internal monthly audit is carried out.

After each audit, the result is displayed on a placard on the factory floor, so that workers can observe the improvements and fight for more improvement actions, see figure 7 .

Table 5. MTTR (h), MTBF (h), Availability and OEE (\%) values in the previous year (y-1) and in the year under study (y)

\begin{tabular}{|c|c|c|c|c|c|c|c|c|}
\hline & \multicolumn{2}{|c|}{ MTTR (h) } & \multicolumn{2}{|c|}{ MTBF (h) } & \multicolumn{2}{|c|}{ Availability (\%) } & \multicolumn{2}{|c|}{ OEE (\%) } \\
\hline & $y-1$ & $y$ & $y-1$ & $y$ & $y-1$ & $y$ & $y-1$ & $y$ \\
\hline CNC Lathes & 4,2 & 3,1 & 920,3 & 1156,5 & 90 & 92 & 49 & 54 \\
\hline $\begin{array}{l}\text { CNC Milling } \\
\text { Centers }\end{array}$ & 5,9 & 4,3 & 1533,1 & 1782,4 & 90 & 92 & 56 & 61 \\
\hline
\end{tabular}

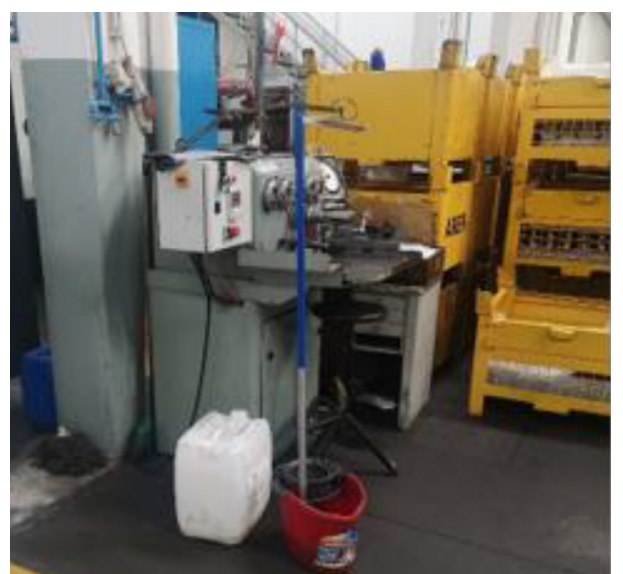

(a)

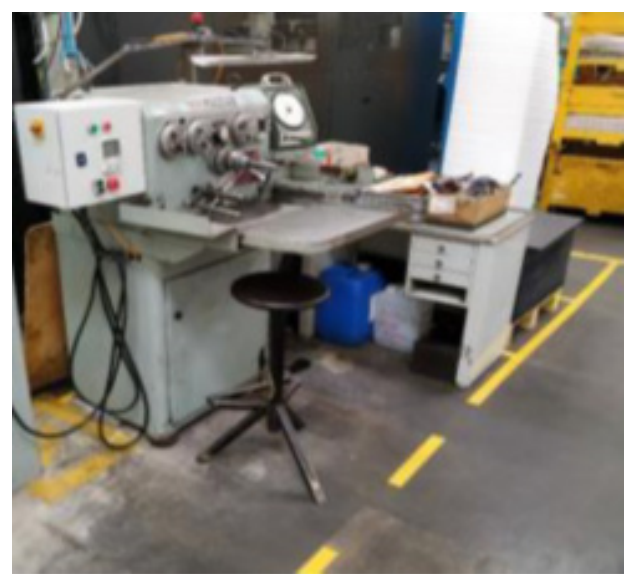

(b)

Figure 6. Before the implementation of the $5 \mathrm{~S}(\mathrm{a})$ after $(\mathrm{b}$

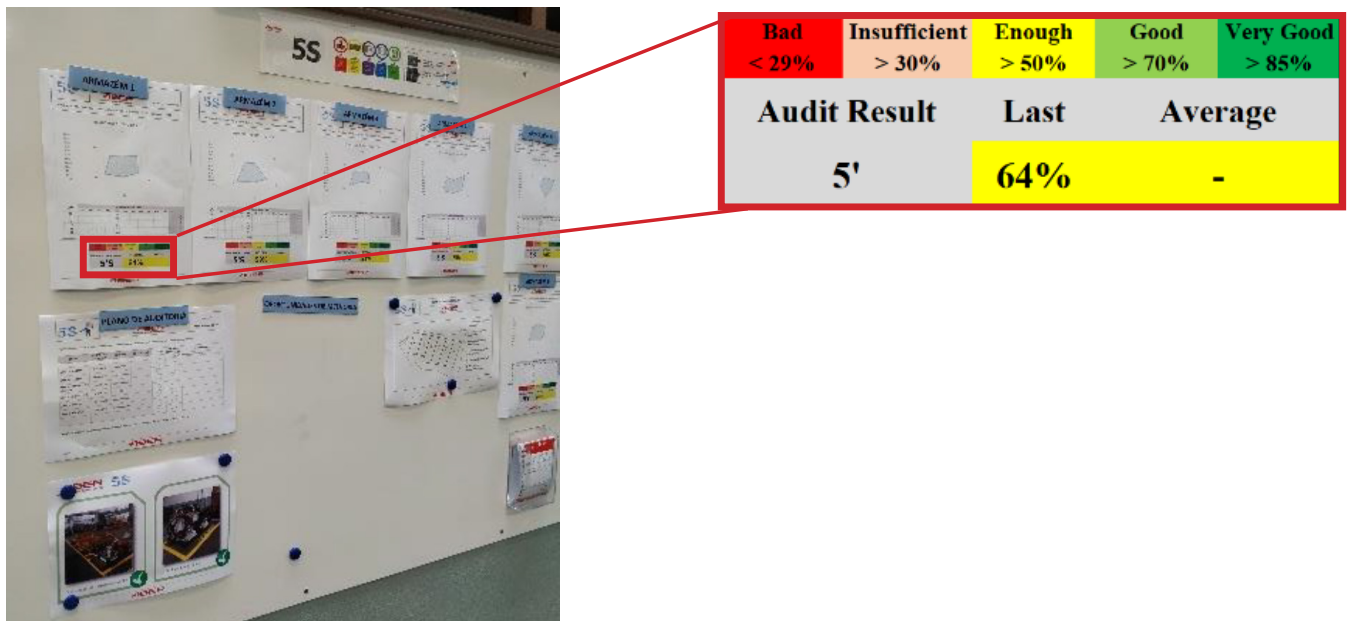

Figure 7. 5S evaluation exposed on the factory floo 


\section{Conclusions and future work}

\subsection{Conclusions}

The organization's success depends directly on a good maintenance management system. Understanding maintenance in a global way can allow greater efficiency, for example, responding more quickly to a malfunction, avoiding the repetition of the problem by eliminating its cause. Thus, a reduction in costs, greater availability and useful life of the equipment is provided.

This work aimed to show that partial implementation of the TPM, namely acting just in some pillars, can provide very positive results. Indeed, it is difficult to start from the zero in traditional companies and try to get the best results in a short period of time.

At the beginning of this work, the biggest concern was the high number of curative interventions, being one of the main goals to decrease that number by $20 \%$. After the implementation of the $5 \mathrm{~S}$ methodology in the CNC milling centres has been achieved, a reduction of $38 \%$ on curative maintenance actions was attained. In CNC lathes, the objective was almost achieved, reaching $17 \%$. The second objective, the reduction of the number of machines' breakdowns was successfully achieved with the implementation of AM, PM and stock management plans, namely consumables and spare parts. Breakdowns due to damage decreased by $23 \%$ and $38 \%$ in the CNC lathes and CNC milling centres, respectively. The last objective is still being worked on. The time required to carry out monthly maintenance has not yet been significantly reduced, trying to complete all the actions needed within a shift.

After the implementation of the planned actions, an evaluation was observed in the indicators OEE, MTTR and MTBF. Table 6 shows how the MTTR, MTBF, Availability and OEE indicators have been improved. These results were calculated according to Moreira et al. [9].

After all the work on implementing the TPM, it is very important to expand this implementation to other pillar but keeping under control the whole achievements already reached. Some important steps have been taken to initiate a change in work philosophy. In this sense, all responsibilities were distributed as well as information and working methods have been properly organized. Internal monthly audits were also scheduled to ensure the continuity of the process. The OEE value achieved is poor, regarding the worldwide reference value of $85 \%$ [1], thus, the efforts should be continued in order to improve the different factors affecting the OEE indicator: quality, availability and performance.

As discussed in section 2, some papers have presented positive results, such as the OEE of the study described Moreira et al. [9], who presented an increase of $2 \%$, i.e., lower than the obtained in this work. However, other authors have presented more appealing results, such as Guariente et al. [19] who have achieve an increase of $12 \%$ (from $70 \%$ to $82 \%$ ), or the value of $74 \%$ achieve by Dias et al. [27], corresponding to an improvement of $21 \%$. The MTBF, MTTR and availability studied by Ribeiro et al. [5] also improved by $25 \%, 13.3 \%$ and $1.2 \%$, respectively, values that are close to the ones obtained through this work. Usually, dramatic decreases of the breakdown times only are reached making technical updates in the hardware of the machines, improving its performance and eliminating some well-known problems. Just using management tools, the results are more modest, but the costs involved are usually insignificant compared to hardware updates. Thus, it can be considered that results achieved by this work are in line with other works developed in other types of industries [28], and only four of the eight TPM pillars were considered, remaining a large room for improvement. Moreover, it can be observed that the time from the implementation to the results collection was short, because to change the mindset of the workers is something hard to achieve. However, after the first results, their willingness to participate in the improvement process is clearly higher.

Depending, always on the starting point of the TPM implementation, some companies present extraordinary improvements and others some modest improvements, but in comparison with the results

Table 6. Indicators' evolution

\begin{tabular}{lcc}
\hline & CNC Lathes & CNC Milling centers \\
\hline MTTR [\%] & -28 & -27 \\
MTBF [\%] & +21 & +14 \\
Availability [\%] & +2 & +2 \\
OEE [\%] & +5 & +5 \\
\hline \hline
\end{tabular}


presented in this work, it is possible to say that the results obtained are positive and within the expected. In any case, the implementation of the TPM is an ongoing process, where the entire structure must participate in a participative and committed manner. It is worth no note that OEE improvements are usually related to lacks of industrial organization or lacks of study on the setups. Thus, $5 \mathrm{~S}$ and SMED tools are usually closely linked to the benefits achieved by the application of TPM methodology, even partially, as in the case of this study.

\subsection{Proposal for future work}

Implement a maintenance management system that has an efficient and effective auxiliary computer system. It is necessary to provide for the creation of alerts, create a history of interventions, and also have a part in the management of spare parts stocks. It is important to record the problems detected regarding the failures in order to understand the history and develop appropriate preventive actions.

Training on TPM and Lean should be given to all workers, from the shop floor to the head to ensure the use and implementation of these tools and also to create a common commitment to well-defined objectives. Communication at the same level, between maintenance and production workers, as well as vertically, with the head, must be improved.

With the AM implementation, workers are empowered to solve the simplest issues and maintenance workers can focus on the most demanding preventive and predictive maintenance.

\section{Funding}

This research did not receive any specific grant from funding agencies in the public, commercial, or not-for-profit sectors.

\section{References}

[1] G. Pinto, F. J. G. Silva, R. D. S. G. Campilho, R. B. Casais, A. J. Fernandes, A. Baptista," Continuous improvement in maintenance: a case study in the automotive industry involving Lean tools". Procedia Manuf., vol. 38, pp. 1582-1591, 2019, doi: 10.1016/j.promfg.2020.01.127.

[2] T. Santos, F. J. G. Silva, S. F. Ramos, R. D. S. G. Campilho, L. P. Ferreira, "Asset priority setting for maintenance management in the food industry," Procedia Manuf., vol.38, pp. 1623-1633, 2019, doi: 10.1016/j.promfg.2020.01.122.

[3] P. Neves, F. J. G. Silva, L. P. Ferreira, T. Pereira, R. M.
Gouveia, C. Pimentel, "Implementing lean tools in the manufacturing process of trimming products," Procedia Manuf., vol.17, pp.696-704, 2018, doi: 10.1016/j.promfg.2018.10.119.

[4] M. D. O. Reis, R. Godina, C. Pimentel, F. J. G. Silva, J. C. O. Matias, "A TPM strategy implementation in an automotive production line through loss reduction," Procedia Manuf., vol. 38, pp. 908-915, 2019, doi: 10.1016/j.promfg.2020.01.173.

[5] I. M. Ribeiro, R. Godina, C. Pimentel, F. J. G. Silva, J. C. O. Matias, "Implementing TPM supported by $5 \mathrm{~S}$ to improve the availability of an aautomotive production line," Procedia Manuf., vol. 38, pp. 1574-1581, 2019, doi: 10.1016/j.promfg.2020.01.128.

[6] R. Thorat, G. Mahesha, "Improvement in productivity through TPM implementation", Materials Today: Proceedings, vol 24, pp. 1508-1517, 2020 doi: 10.1016/j.matpr.2020.04.470.

[7] A. Sharma, A. Joshi, V. Jurwall, "Performance measurement metrics in TPM: A contextual view to training and development”, Materials Today: Proceedings, vol 28, pp. 2476-2480, 2020 doi: 10.1016/j.matpr.2020.04.796.

[8] M. Suryaprakash, M. Prabha, M. Yuvaraja, R. Revanth, "Improvement of overall equipment effectiveness of machining centre using tpm", Materials Today: Proceedings, 2020, doi: 10.1016/j.matpr.2020.02.820

[9] A. Moreira, F. J. G. Silva, A. I. Correia, T. Pereira, L. P. Ferreira, F. Almeida, "Cost reduction and quality improvement in the printing industry," Procedia Manuf., vol. 17, pp. 623-630, 2018, doi: 10.1016/j.promfg.2018.10.107.

[10] C. Rosa, F. J. G. Silva, L. P. Ferreira, "Improving the quality and productivity of steel wire-rope assembly lines for the automotive industry," Procedia Manuf., vol. 11, pp. 11351142, 2017, doi: 10.1016/j.promfg.2017.07.214.

[11] R. F. L. Santos, F. J. G. Silva, R. M. Gouveia, R. D. S. G. Campilho, M. T. Pereira, L. P. Ferreira, "The improvement of an APEX machine involved in the tire manufacturing process," Procedia Manuf., vol. 17, pp. 571-578, 2018, doi: 10.1016/j.promfg.2018.10.098.

[12] S. Ferreira, F. J. G. Silva, R. B. Casais, M. T. Pereira, L. P. Ferreira, "KPI development and obsolescence management in industrial maintenance," Procedia Manuf., vol. 38, pp. 1427-1435, 2019, doi: 10.1016/j.promfg.2020.01.145.

[13] A. Morimoto, Y. Sato, S. Takata, "Continuous Improvement of Criteria for Condition-based Maintenance by Means of Effects Evaluation of Treatments," Procedia CIRP, vol. 61, pp. 293-298, 2017, doi: 10.1016/ j.procir.2016.11.266.

[14] BS EN 13306:2010 - Maintenance - Maintenance terminology. British Standard Institution, London, UK, 2010.

[15] Monchy, F. La fonction maintenance : Formation à la gestion de la maintenance industrielle. Elsevier Masson, Paris, pp. 15-77, 1996. ISBN 2-225-85518-8.

[16] C. Lundgren, A. Skoogh, J. Bokrantz, "Quantifying the effects of maintenance: a literature review of maintenance models," Procedia CIRP vol. 72, pp. 1305-1310, 2018, doi: 10.1016/j.procir.2018.03.175.

[17]J. Coetzee, "A holistic approach to the maintenance "problem", Journal of Quality in Maintenance Engineering vol. 5(3) pp. 276-281, 1999, doi: $10.1108 / 13552519910282737$.

[18] Courtois A, Pillet M, Martin-Bonnefous C. Gestão da Produção (in Portuguese), Lidel - Edições Técnicas, Lda., Lisboa, Portugal, 2006. ISBN: 9789727574698.

[19] P. Guariente, I. Antoniolli, L. P. Ferreira, T. Pereira, F. J. G. Silva, "Implementing autonumous maintenance in au 
automotive components manufacturer," Procedia Manuf., vol. 13, pp. 1128-1134, 2017, doi: 10.1016/j.promfg.2017.09.174.

[20] F. L. Cooke, "Implementing TPM in plant maintenance: some organizational barriers," International Journal of Quality \& Reliability Management, vol. 17 No. 9, pp 1003-1016, 2000, doi: 10.1108/02656710010378789.

[21] A. H. Bakti, A. R. A. Rahim, N. M. Yusof, R. Ahmad, "Booting Lean production via TPM," Procedia - Social and Behavioral Sciences, vol. 65 pp. 485-491, 2012, doi: 10.1016/j.sbspro.2012.11.153.

[22] K. Antosz, L. Pasko, A. Gola, "The Use of Intelligent Systems to Support the Decision-Making Process in Lean Maintenance Management” IFAC-PapersOnLine, vol. 52(10) pp. 148-153, 2019, doi: 10.1016/j.ifacol.2019.10.037.

[23] P. Ribeiro, J. C. Sá, L. P. Ferreira, F. J. G. Silva, M. T. Pereira, G. Santos, "The Impact of the Application of Lean Tools for Improvement of Process in a Plastic Company: a case study," Procedia Manuf., vol. 38, pp. 765-75, 2018, doi: 10.1016/j.promfg.2020.01.104.

[24] C. Costa, L. P. Ferreira, J. C. Sá, F. J. G. Silva, "Implementation of $5 \mathrm{~S}$ methodology in a metalworking company," DAAAM International Scientific Book, pp. 001012, 2018, doi: 10.2507/daaam.scibook.2018.01, ISBN 978-3-. 902734-19-8, ISSN 1726-9687

[25] IATF 16949:2016 - Quality management system requirements for automotive production and relevant service parts organization, IATF - International Automotive Task Force, 2016.

[26] T. Pombal, L. P. Ferreira, J. C. Sá, M. T. Pereira, F. J. G. Silva, "Implementation of Lean methodologies in the management of consumable materials in the maintenance workshop of an industrial company," Procedia Manuf., vol. 38, pp. 975-982, 2019, doi: 10.1016/j.promfg.2020.01.18.

[27] P. Dias, F. J. G. Silva, R. D. S. G. Campilho, L. P. Ferreira, T. Santos, "Analysis and Improvement of an Assembly Line in the Automotive Industry, " Procedia Manuf., vol. 38, pp. 1444-1452, 2019. doi: 10.1016/j.promfg.2020.01.143.

[28] E. Sousa, F. J. G. Silva, L. P. Ferreira, M. T. Pereira, R. Gouveia, R. P. Silva, "Applying SMED methodology in cork stoppers production,” Procedia Manuf., vol. 17, pp. 611-622, 2018. doi: 10.1016/j.promfg.2018.10.103. 